\title{
QUALITY EVALUATION AND SURVEY OF THE ESSENTIAL NEED FOR DRUG INFORMATION CENTERS
}

\author{
MING MING WEN ${ }^{a}$, HEBA AREF ${ }^{b}$, AHMED ABOZAIDa , NAHLA HESHAM KANDILc, YASMIN HUSSEIN ELSOBKY $^{d}$ \\ aFaculty of Pharmacy, Pharos University in Alexandria, Alexandria, Egypt, bHarrison School of Pharmacy, Auburn University, Auburn, \\ AL,USA, cClinical Pharmacy Department, MOH Hospitals, Egypt, dDrug Information Consultant
}

Email: mingming.wen@pua.edu.eg

Received: 13 Jul 2016 Revised and Accepted: 09 Sep 2016

\begin{abstract}
Objective: The first objective of this work was to examine the services provided by six drug information centers (DICs) in Alexandria, Egypt. The second objective was to evaluate the quality of the replies to the drug information query. The third objective was to assess the conceptual need of DICs from community pharmacists, other health care professionals and the general public.
\end{abstract}

Methods: This study was conducted through three stages. Stage I was a field survey to assess predefined parameters in the current DICs in Alexandria. Stage II was a retrospective cross-sectional study to assess the quality of the drug information replies through an external expert review process. Stage III was a population survey and thematic analysis using questionnaires and interview recording.

Results: Activities of DICs include: DIR answering service (100\%), adverse drug reaction reporting (100\%), issuing bulletins (83.3\%), education $(83.3 \%)$, drug use evaluation (50\%) and participation in P and T committees (33.3\%). The most frequent question categories asked were dosing, side effects, treatment guidelines and drug interactions. Half of the DICs were affiliated with hospitals; however, a general lacking confidence level of these DICs on the professionalism and the impact on patient care for the DIC services provided was identified. There was an obvious problem in formatting the ultimate question in a question format rather than a sentence format in all DICs. The most accurately answered request was adverse drug reactions. All surveyed groups considered that it is very important to have a DIC accessible to the community free of charge.

Conclusion: It is necessary to establish an university-based DIC to incorporate training, education and research into the existing services. A DIC network with definitive standards of services in the future should provide safe and effective quality-assured pharmaceutical care to meet the needs and expectations of the community and improve its delivery to the public. The results and recommendations of this study can be inspired and generalized to other developing countries that have similar health systems as in Egypt.

Keywords: Drug information center, Thematic analysis, Survey, Quality evaluation, Questionnaire, Egypt

(C) 2016 The Authors. Published by Innovare Academic Sciences Pvt Ltd. This is an open access article under the CC BY license (http://creativecommons.org/licenses/by/4. 0/) DOI: http://dx.doi.org/10.22159/ijpps.2016v8i11.14085

\section{INTRODUCTION}

Drug information centers (DICs) have been established for more than $50 \mathrm{y}$ in the U. S. since the first DIC started at the University of Kentucky Medical Center in 1962 [1, 2] and 1970s in UK [3] to provide drugrelated information to healthcare professionals or general publics for the better patient care outcome. Nowadays DICs have been operated by pharmacists in many countries worldwide. In 1973, the first national survey identified 54 DICs existing in USA, and the number was then increased to 120 in 1992 and 151 in 2004 according to published reports $[4,5]$. It was reported that DICs in Europe were mainly affiliated with hospitals, whereas a comparatively less affiliation with a faculty of pharmacy or faculty of medicine [6]. This finding was different from the situation in the US [1], where most of the DICs were located at the faculties of pharmacy and was in concordance with the previous surveys in Europe $[7,8]$ where the number of DICs within a faculty of pharmacy was lower than within a faculty of medicine. It was not clear, however, why there were so few DICs under the umbrella of the faculty of pharmacy in Europe.

Drug information centers provide comprehensive, unbiased drug information to meet the needs of clinicians, pharmacists, and other healthcare professionals. Nowadays the dramatic increases of new pharmaceuticals are pumping into the drug market every year. Although, this has given prescribers more variety alternatives of therapeutic choices; it also created a grey zone of the ambiguity of the evidence and therapeutic outcome provided. It is important for well-trained DIC pharmacists to select appropriate resources using a systematic approach and keep current on new guidelines and evidences to respond different drug information requests. Patients, on the other hand, are becoming more aware and involved in their own healthcare by searching medicine information independently via the Internet, whether or not accurate which could have resulted in the erroneous conclusion drawn from insufficient or promotional information. In this regard, services provided by professional DICs are essential to fulfilling the medical information need for both health care providers and patients.

The World Health Organization (WHO) stated that DIC is a core component of national programs to promote the rational use of drugs [9, 10]. Other organizations such as The International Pharmaceutical Federation (FIP), United States Pharmacopeia (USP) and Food and Drug Administration (FDA) also issued similar definition regarding the drug information services [11]. One cannot deny that a major gap still exists between evidence and best practice in pharmacotherapy in both rich and poor countries under the current health care system worldwide [12-15]. There is a great need to improve further the drug therapy selection and dosage to prevent the risk of adverse effects and improve patient care outcome. This need has been brought up repeatedly over the years following a study reported by Bergman and Wiholm in 1981 [16-18].

In Egypt, there is an imbalance between promotional information and professional information on medicines for consumers and health care providers. They both receive a lot of advertisements for drugs, directly or indirectly from various resources. National health policies are industry-focused rather than individual health-focused. The Egyptian healthcare system was reported facing many challenges and the diversity of Egyptian pharmaceutical market made it very difficult for healthcare practitioners to be fully aware in making treatment decisions [19]. The DICs in Egypt have not been established in most hospitals, public and private. Weak drug regulations and lack of independent, unbiased drug information 
resources are the main contributing factors for irrational drug use commonly seen in Egypt. Most health professionals do not have access to reputable drug information database in their working places and most of them are not trained to evaluate the information received critically. This leads to irrational selection, prescribing, dispensing and consumption of medicines, which could potentially harm patients and negatively impact their health care outcomes. In fact, the demand from both the health care professionals and patients for reliable validated drug information is increasing recently in Egypt. The Ministry of Health has set up a goal to implement clinical pharmacy and drug information centers in all hospitals under its supervision; however, no national survey regarding the performance of the existing DICs has been researched. Neither governmental data nor private research reports have been addressed the current status of drug information centers. Very limited information is available regarding the activities, resources, personnel qualification and the quality of services provided by these DICs. Therefore, it was needed to address the public expectations and satisfaction with regard to the services received, and the quality of drug information replies from these DICs in order to improve pharmaceutical care delivery to the Egyptian public.

This study was aiming at assessing various aspects relevant to drug information centers in Alexandria governorate in Egypt. Alexandria is the second largest city in Egypt after the capital Cairo by size and number. It has a population of 4.5 million, extending about $32 \mathrm{~km}$ along the coast of the Mediterranean Sea [20]. Drug information centers are not well known among the population and are generally ignored by the health care providers. The objectives of the study were three folds. The first objective was to examine and identify the existing services provided by the six current running DICs in Alexandria at the time of this study. The second objective was to evaluate the quality of the replies to the drug information query. The third objective was to assess the conceptual need of DICs from the perspectives of health care professionals, community pharmacists and the general public in Alexandria.

\section{MATERIALS AND METHODS}

This study was conducted through three stages according to the objectives to assess various aspects relevant to drug information centers during the one year study period (January to December 2014). Stage I was a field survey to assess predefined parameters in the current pharmacist-operated DICs in Alexandria. Stage II was a retrospective cross-sectional study to assess the quality of the drug information replies from the DICs through an external expert review process. Stage III was a population survey and thematic analysis using questionnaires and interview recording to analyze the conceptive need of DICs from the points of community pharmacists, health care professionals and general publics.

\section{Inclusion criteria}

The target populations were DICs in Alexandria. A drug information center (DIC) was defined as a center that routinely receives drug information requests from health care professionals and publics ${ }^{5}$. We identified six DICs that met our inclusion criteria according to the information provided by the Alexandria Pharmacy Syndicate and Ministry of Health, including Ras ElTin Hospital, Fever Hospital, Anfushi Hospital, Health Insurance Hospital, Amrawy health unit and Alexandria pharmacy syndicate. Since the target population was small and easy to contact, it was feasible to survey the entire population; thus sampling process was not required. However, at stage III which assessed the health and therapeutic information need, samples of patients, pharmacists and other health care professionals in different settings in Alexandria were included.

\section{Stage I: Evaluation of the current status of DICs}

A cover letter presenting the aims of this study and the research team was sent to the manager of each DIC to acquire the written consent in participating in this study. The research instrument used to collect data was a 6-category questionnaire, including general information about the drug information center, services and activities, resources, training and education, research and quality assurance and documentation with a total of 45 items. Questions consisted of a mixture of multiple-choice, open-ended, 2-way close ended questions and a Likert scale question. Three interviewers were randomly assigned to interview face-to-face the manager of the DIC. Interviewers first explained the survey questions and had a deeper discussion with the interviewer throughout the interview session. The completion of each interview took about 20-30 min. There was no camouflage to the identity of the DIC, location or respondents. Descriptive statistics were used for data analysis.

\section{Stage II: Quality assessment of the replies provided by the DICs}

A retrospective cross-sectional evaluation of drug information requests documented in each DIC was carried out through an external review process by a DIC expert who was invited by the authors. A specific evaluation template designed by the authors using ASHP guidelines was used for all responses. The assessment form consisted of three parts. Part I assessed the documentation, search strategy, written response, references, and the quality of the response through a Likert-scale from 1 to 5 where 1 denoted poor, and 5 denoted excellent. Part II was a check list box for different question types to evaluate the most accurately answered versus the least accurately answered requests [21]. The last part was an open section for the evaluator to add remarks on the DI response (Appendix). Since the DICs included in this study were established either in 2013 or 2014, all the enquiries and responses filed from January 1 to December 31, 2014, were obtained for evaluation due to the small number of requests received. One DIC was not able to open the drug information files to the authors due to institutional policy. Thus, a total of 172 drug information inquiries and replies were evaluated from the 5 DICs.

\section{Stage III: Population survey and thematic analysis of the need of drug information centers in Alexandria}

\section{Population survey}

To identify the drug information need in the community, three questionnaires were developed as the instruments and data were collected by interview face-to-face in three groups of population, namely community pharmacists, health care professionals and the general publics in May 2014. The title and an introductory page explaining the aims of this study were presented to the participants prior to the interview. The context stated that their opinions will be used to improve drug information services in the community. Also, it assured that responses will be kept strictly confidential. The questionnaire included three categories: baseline data of the interviewee, drug information questions received and the need to check the resources for these questions, and the perception of the need to contact a DIC for further assistance. The format included tick box closed option and fill-in questions. Core questions were the same for all three groups with minor variations in questions addressed to a specific target group. Participants were anonymous and ensured the confidentiality. An identifier code was given to each individual respondent. Samples were randomly selected from different districts in Alexandria to avoid the bias. Physicians, dentists, nurses were randomly selected from both governmental and private hospitals. Pharmacists were from community pharmacies excluding the chain pharmacies. General publics were adult populations either patients or non-patients. Every tick box of the returned form was assigned a response code in order to enter into a dataset.

\section{Thematic analysis}

A recorded interview to identify the major theme among the interviewees was also conducted by audio-recording the whole interview conversation to provide an accurate record of the verbal communication that occurred during the interview in order to allow detailed thematic analysis later on. This was done in the same three target groups as mentioned previously, with 5 recordings in each group. An interview guide was developed which contained 5 openended questions with subject headings, directly or indirectly related to our investigated issue, to assist the interviewer to control and conduct the interview process actively. Before the interviews, participants were clearly informed about the aim and process of thematic analysis of their responses, the importance of participating 
in the survey and ensuring that their recording will be kept strictly confidential.

The framework analysis of the interviews was adapted from the key stages of qualitative data analysis [22-24] and modified by means of generic qualitative methods [25]. The dialogue from each interview was first transcribed into texts which were analyzed into themes to obtain the results. Each transcript was read out loud to label relevant words or sentences in a meeting by the authors. Any ideas or topics in the data were identified and categorized into themes. All the survey questionnaires and interview protocol in this study were approved by the Research Ethics Committee of Pharos University in Alexandria.

\section{Data analysis}

Stage I and II results were analyzed with descriptive statistics using a percentage value. The reliability of Likert scale items was first checked with a Cronbach's alpha. The obtained Cronbach's $\alpha$ for the self-evaluation sample's score was 0.976 which indicated that the measuring instrument had reliability to measure consistently [26]. Stage III results of the population survey involved the use of chisquare test of independence to compare categorical variables to measure the difference between groups. Statistical Package for the Social Sciences (SPSS) version 20.0 (SPSS, Inc., an IBM Company, Chicago, IL) was used to perform the statistical tests. A statistically significant level was set at $\mathrm{P}<0.05$.

For population survey in stage III, a published guide concerning the sample sizes in qualitative research declared that samples ranging in size from 10 to 40 per group were adequate in providing estimates precision to meet a variety of possible aims [27]. Further estimation of sample size by GraphPad StatMate 2.0 indicated a sample size of 30 in each group was sufficient to achieve a $95 \%$ power with a significance level (alpha) of 0.05 (two-tailed). Hence, the initial survey sample was set to 30 for each group with a total of 90 respondents.

\section{RESULTS AND DISCUSSION}

\section{Stage I: Evaluation of the current status of DICs}

\section{Affiliation and activities}

Half of the DICs in Alexandria were affiliated with hospitals. One was run by the local pharmacists' syndicate, and two DICs were in outpatient-based health organizations. Neither the faculty of pharmacy nor the primary teaching university hospital had a current active DIC. Activities of DICs mainly included drug information request answering service $(100 \%)$, adverse drug reaction reporting $(100 \%)$, issuing newsletter/bulletins (83.3\%) and offering education to nurses and patients (83.3\%). About half of the DICs participated in hospital committees including family medicine and updating treatment guidelines; however, none shared in a Pharmacotherapeutic $(\mathrm{P} / \mathrm{T})$ committee. There were no research activities conducted in these DICs and no faculty members were participating in any DIC activities. Interestingly, peer communication on the Internet was mainly through Facebook and none of the DICs had created its own website at the time of the study. In the governmental hospitals, the directing board members, mainly physicians, were still lacking trust in the pharmacists to grant them more authorities to share in the hospital decisionmaking processes.

\section{Personnel}

Pharmacists in the DIC are specialized in the field of information about drugs. To accurately answer DIC questions on various topics, it is not enough for a DIC pharmacist to hold only a bachelor degree. DIC pharmacists need more training in retrieving and critically appraising the medical information. The results showed that a total of 26 employees, all being pharmacists, worked in these 6 DICs. Each center employed 2-4 pharmacists, with 1-3 of them being full-timers. One center had 14 working pharmacists, among whom only 2 were full-timers. All centers had at least one pharmacist with Pharm D or Master Degree in clinical pharmacy, except for one center which had pharmacists holding a one-year post-graduate study in hospital pharmacy. Half of the 26 pharmacists were currently studying for a diploma in hospital pharmacy or clinical pharmacy at the time of the survey. Two pharmacists were American Board certified. Only 3 DICs required initial training in a DIC before hiring and the training period ranged from 1-6 mo. In general, younger pharmacists were satisfied with the DIC training that they received. However, there was no quality assurance unit to audit the DIC activities. The transferrable knowledge gained from the training into the qualified care outcome is often difficult to be measured without appropriate quality control experts' guidance in the affiliated organizations.

\section{Requests}

The documented requestors included physicians, pharmacists, nurses, patients and family of the patient. Number of requests received ranged from 4 to 48 per month. The types of queries predominantly related to dosage, drug interactions, adverse effects, therapeutic use, treatment guideline and IV compatibility/stability. These data could point to the clinical orientation of the DI requests presented to the six centers. All the DICs used one or more methods for documenting the requests. There was no standard request form shared among these DICs. Each DIC had its own in-house designed DIC request form. Four centers required pharmacists to fill printed templates; three had hard copies printed from soft copies to be filed; one had soft copy only, and one used handwriting without printed template. Only one DIC used Google Drive to share and prepare collective data documentation.

\section{Resources}

There was no standard or specific resources required by the affiliated organization to be housed in the DIC. All DICs shared a collection of e-books on a CD-ROM; however, no printed sources were available. Overall, a total of 13 e-books, 2 electronic drug information databases (full-text), and 18 free internet websites were identified. Top-reported e-books were BNF, Stockley's Drug Interactions, Martindale: The Complete Drug Reference, Pharmacotherapy: A Pathophysiologic Approach, and Applied Therapeutics: The Clinical Use of Drugs. Two electronic drug information databases were Up To Date and Lexi-Comp which were subscribed by one organization. This could be attributed to limited financial resources needed for a full subscription. EMBASE, MEDLINE, NICE guidelines were also used for searching the primary literature. Commonly used free internet websites included Medscape, Globalrph, Epocrates and Drugs. Com. Regarding Egyptian Ministry of Health website, unfortunately, it was not updated and some of the treatment guidelines were not accurate when accessed at the time of this study.

\section{Fees}

All the DICs were not funded or financially supported by the organizations to which they were affiliated. Some of the computers were donated from Alexandria Pharmacy Syndicate. There was no charged fee for any of the activities provided by the DICs.

\section{Self-evaluation}

The result of self-evaluation scores was presented in fig. 1which indicated a general lacking confidence level of these DICs on the professionalism and the impact on patient care for the DIC services provided. All these DICs were newly established which gave space to develop and improve their services in the future.

\section{Stage II: Quality assessment of the replies provided by the DICs}

A total of 172 replies from the 5 DICs were blinded and evaluated by the expert. Table 1 presented the results of expert evaluation by Likert scale. There were significant differences between the evaluation scores among these 5 DICs by Kruskal-Wallis test with post test $(p<0.0001)$ which indicated the divergent performance of drug information replies in different DICs. The highest scores obtained in DIC-1 were $64.21 \%$ satisfaction, while the weakest performance in DIC- 5 had only $28.42 \%$ of the expectation. 


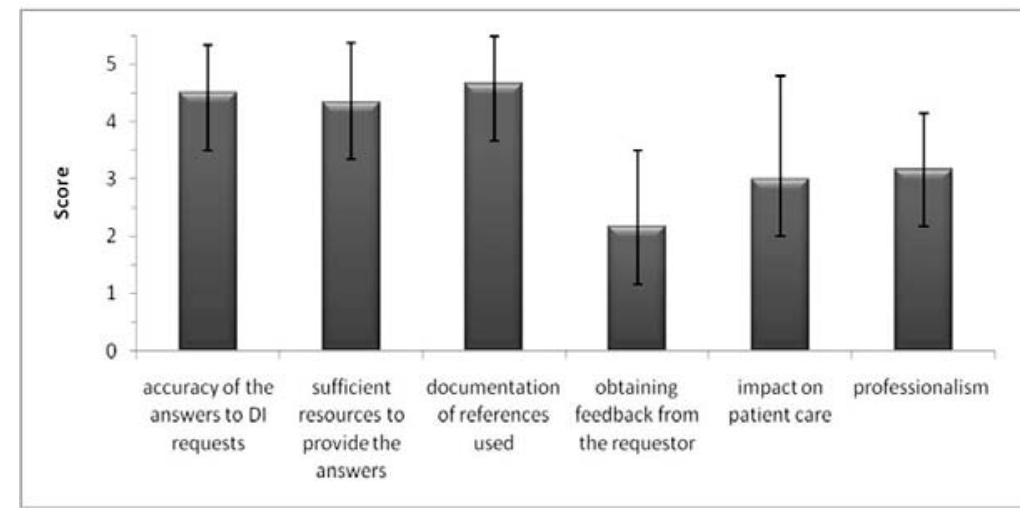

Fig. 1: Self-evaluation scores by the surveyed DICs $(n=6$, mean \pm SD) $(1=$ the weakest $2=$ weak $3=$ average $4=$ strong $5=$ the strongest $)$

Table 1: Expert evaluation rubrics and scores on the drug information reply, (1=poor $2=$ =fair $3=$ =good $4=v e r y$ good $5=e x c e l l e n t)$

\begin{tabular}{|c|c|c|c|c|c|c|}
\hline & & DIC-1 & DIC-2 & DIC-3 & DIC-4 & DIC-5 \\
\hline \multirow[t]{5}{*}{ Documentation } & identification of the caller & 4 & 4 & 2 & 4 & 3 \\
\hline & - requestor's demographic data & 2 & 1 & 1 & 2 & 1 \\
\hline & - patient background information & 1 & 1 & 1 & 1 & 1 \\
\hline & - initial question and ultimate questions & 1 & 1 & 1 & 1 & 1 \\
\hline & - request categorization & 1 & 1 & 1 & 1 & 1 \\
\hline \multirow[t]{3}{*}{ Search strategy } & - correct information sources used & 5 & 2 & 3 & 3 & 2 \\
\hline & search strategies & 4 & 2 & 3 & 3 & 2 \\
\hline & $\begin{array}{l}\text { enough numbers of resource that were used to answer the } \\
\text { questions }\end{array}$ & 5 & 2 & 2 & 2 & 1 \\
\hline \multirow[t]{3}{*}{ Written Response } & correct response & 5 & 3 & 3 & 3 & 2 \\
\hline & - logical reasoning & 4 & 1 & 3 & 2 & 2 \\
\hline & - use evidence-based recommendation with critical appraisal & 3 & 1 & 1 & 3 & 1 \\
\hline \multirow{2}{*}{ References } & appropriate selection of the references & 5 & 3 & 3 & 4 & 2 \\
\hline & - appropriate citation & 3 & 1 & 2 & 1 & 1 \\
\hline \multirow[t]{6}{*}{ Quality of the response } & - accuracy & 4 & 2 & 2 & 2 & 2 \\
\hline & - completeness & 4 & 1 & 2 & 3 & 1 \\
\hline & clarity & 3 & 1 & 1 & 1 & 1 \\
\hline & objectivity & 3 & 1 & 1 & 2 & 1 \\
\hline & - impact on patient care & 3 & 1 & 1 & 2 & 1 \\
\hline & - clearly document follow-up response & 1 & 1 & 1 & 3 & 1 \\
\hline
\end{tabular}

All the participated DICs identified the caller by the profession without stating the specialty of the physician. Most of the DICs lacked important information on the request form according to the evaluation rubrics. None of the DICs categorized question type; while most of the requests lacked background information, a major defect for DICs in the developing countries [28]. Most of the DICs gave replies without further background information checking. Expert opinion reflected an obvious problem in formatting the ultimate question in a question format rather than a sentence format in all DICs.

Concerning searching strategy, most of the DICs used only one of the correct several sources of information. The searching strategy was not clearly stated on the request form to evaluate it. The majority of the DICs reported only one reference in verifying the information obtained. Regarding the written response, nearly all of the requests were answered correctly, however lacking the details and properly written presentation.

Many of the answers were shown by copy/paste the information from the resource without further modification. Many spelling and grammar mistakes were found as well as using abbreviations not explained in the text. Overall quality of responses differed from one request to another. Some of the answers were not patient-specific while others were out of the topic. The main reason for this limitation was the absence of the proper background information checking to aid in tailoring the information to the patient needs. The most accurately answered requests were those pertaining to adverse drug reactions, teratogenicity, injectable drug compatibility, and drug-drug interactions. The least accurately answered questions were product identification which may be due to lack of product identification database for locally produced pharmaceuticals.

Stage III: Population survey and thematic analysis of the need of drug information centers in Alexandria

\section{Population survey}

Part of the problem in health care in Egypt is that most patients do not have enough knowledge of medicines which they are taking. Physicians were not trained in the university to follow evidencebased medicine practice in which patients should be involved in the decision-making about their treatment options. There is little defined therapeutic plan built on the institutional health care team based on the communication and the drug knowledge within the health care network. Despite these constraints, for most of the patients, physicians are the preferred initial source of drug information. One should consider the existence of a complex interaction between medicine knowledge, information demands and sources. To be able to effectively connect the dots together to optimize the use and understanding of the medicines by both health care providers and patients, standardized, well-trained professional DICs are needed to provide services to be accessible for all population in Egypt.

Several questions were desired to be answered in this survey regarding how to comprehend the target groups in perceiving the need of a DIC and the types of variable that may influence this perception, such as work experience, the level of education, previous training, professions, age and availability of the resources. 
Table 2 showed the comparison between three studied groups and their perception of the need to have a DIC. The general public expressed a higher level of the need to have a DIC as 'very important'
(73.3\%) than health care professionals. Chi-square test further indicated that all target groups considered that it is very important to have a DIC accessible to the community.

Table 2: Comparison between three studied groups according to the need of a drug information center (DIC)

\begin{tabular}{|c|c|c|c|c|c|c|c|c|}
\hline \multirow[t]{2}{*}{$\begin{array}{l}\text { The need of a drug } \\
\text { information center (DIC) }\end{array}$} & \multicolumn{2}{|c|}{$\begin{array}{l}\text { Community pharmacist } \\
(\mathrm{n}=30)\end{array}$} & \multicolumn{2}{|c|}{$\begin{array}{l}\text { Other health care professionals } \\
(n=30)\end{array}$} & \multicolumn{2}{|c|}{$\begin{array}{l}\text { General public } \\
(n=30)\end{array}$} & \multirow[t]{2}{*}{$\chi^{2}$} & \multirow[t]{2}{*}{${ }^{\mathrm{MC}} \mathbf{p}$} \\
\hline & No. & $\%$ & No. & $\%$ & No. & $\%$ & & \\
\hline Very important & 17 & 56.7 & 15 & 50.0 & 22 & 73.3 & 5.041 & 0.198 \\
\hline Important & 13 & 43.3 & 14 & 46.7 & 8 & 26.7 & & \\
\hline Not very important & 0 & 0.0 & 1 & 3.3 & 0 & 0.0 & & \\
\hline Not at all important & 0 & 0.0 & 0 & 0.0 & 0 & 0.0 & & \\
\hline
\end{tabular}

$\chi^{2}$ : Chi-square test, MC: Monte Carlo

Table 3 demonstrated that parameters such as year of work experience, the level of education, type of profession, the age of the general public and numbers of the patient received per day for health care providers had no influence on their selection of the need of a DIC as very important/important. However, health care providers who had previous drug information retrieval training were more confident in their answering drug information questions, and therefore did not think a DIC was very important/ important. About $86 \%$ of community pharmacists never had training in the drug information retrieval. On the other hand, $45 \%$ of the health care providers other than the pharmacists needed to check the resources before answering drug information questions. Nearly $75 \%$ of the general public have never heard of DIC. Half of the general public preferred to ask the physicians and half of them would ask the pharmacists when they have drug information questions.

Table 3: Relation between the need of a drug information center (DIC) and other parameters

\begin{tabular}{lll}
\hline & $\chi^{2}$ & ${ }^{{ }^{2 C}} \mathbf{p}$ \\
\hline Years of work experience & Community pharmacist 3.815 & 0.249 \\
& Health care professionals 0.339 & 1.000 \\
& General public 1.103 & 0.906 \\
Level of education & Community pharmacist 3.104 & 0.393 \\
& Health care professionals 3.828 & 0.264 \\
& General public 5.113 & 0.411 \\
Type of profession & Health care professionals 0.438 & 1.000 \\
& General public 4.293 & 0.343 \\
Numbers of patient received per day & Community pharmacist 7.022 & 0.142 \\
& Health care professionals 1.597 & 1.000 \\
Age & General public 5.855 & 0.244 \\
Previous training in drug information retrieval & Community pharmacist 4.588 & ${ }^{\text {FE } 0.052}$ \\
\hline
\end{tabular}

$\chi^{2}$ : Chi square test, MC: Monte Carlo, FE: Fisher Exact, $n=30$ for each group

Community pharmacists had higher confidence than other health care providers in answering questions related to drug cost; on the other hand, other health care providers had higher confidence on the drug indication questions than pharmacists. Both community pharmacists and other health care professionals were not able to answer questions related to pregnancy and lactation, adverse drug reaction and drug interaction immediately and needed to search the information further. Surprisingly, IV compatibility questions could be answered immediately which implied that hospital staffs had well-trained knowledge on the IV drugs and that community pharmacists did not receive such type of questions.

Main resources used by $74 \%$ of the health care providers other than pharmacists were textbooks, reference books and free websites, in which $52.6 \%$ of them indicated that they were not satisfied with the resources available and would mostly ask another physician $(80 \%)$ or community pharmacist $(20 \%)$. While $55.17 \%$ of the community pharmacists stated that they felt frustrated when they were not able to access high quality and reliable drug information resources to answer all types of drug information questions. The least used resource was primary literature.

The most preferred way to contact a DIC was by phone $(42 \%)$ and personal contact (38.7\%). Only $19.3 \%$ liked to receive a reply through emails. Those who thought a DIC was very important/important were willing to pay fee-for-service for any request (chi-square test, $\mathrm{p}<0.05$ ), however, $40 \%$ of the general public did not agree to pay and thought that it should be free, same as the services provided by the governmental health care facilities in Egypt.

\section{Thematic analysis}

A number of themes and sub-themes based on the principles of the study objectives emerged from analyzing the transcripts of the dialogue recording. The results could provide insight into the free views of the participants which were not possible to be identified using the preset of the questionnaires. The major themes were collected as described below.

Theme 1: Barriers exist between community pharmacists and physicians

There are seemly barriers existing between the community pharmacists and physicians. Physicians in Egypt do not usually accept a recommendation from a community pharmacist regarding dose changing or alternative therapy. On the other hand, community pharmacists feel that physicians don't see them as professional health care providers.

- "I would ask a DIC, but NOT THE PHYSICIAN." (pharmacist)

- "I would like to call the doctor first to understand why he prescribed this medicine. Some doctors explain, but some don't I think doctors don't trust us." (pharmacist)

- 'I'm not sure about the community pharmacists because I don't think they are up-to-date, but the clinical pharmacists in the hospitals do. I would trust their opinions more." (physician)

- "If the pharmacists are older with more experience, I would listen and discuss with him. But I will NOT discuss a case with a young community pharmacist." (physician) 
Theme 2: Pharmacists see themselves as professional drug information providers

Most of the pharmacists see themselves as professional drug information providers. But this notion is not completely shared by other health care providers and general publics.

- "Of course, we [pharmacists] are the professional drug information providers. That's why we are called PHARMACIST." (pharmacist)

- $\quad$ "My drug information knowledge was very good to handle cases in the daily work. I had drug information retrieval training while working as medical representative advertising new drugs in one of Alexandria's pharmaceutical companies but I think I don't have to know all the information in my mind because simply it's impossible." (pharmacist)

- "I think doctors [physicians] know medicines more. Pharmacists usually just tell me how to take and how many times per day." (patient)

- "We know all the medicines in our specialties. It's our job to select the best medicines for the patients, NOT PHARMACISTS." But the pharmacist can help in telling patients about the side effects and how to take, etc." (physician)

\section{Theme 3: DIC is a rescuer}

A DIC is foreseen by health care providers, including pharmacists as a place that they can ask questions and expect to get the correct answers.

- "I asked the physician in the hospital if I don't know. but it will be GREAT if a professional DIC is available to answer my questions anytime." (nurse)

- "Sometimes I don't know if my answer is $100 \%$ right I will feel better if somebody can double check my answer." (pharmacist)

- 'When I ask my doctors about the medicines, I don't get detailed answers. I think doctors don't have time to tell me everything. I just follow his instruction. If there is a professional DIC for me to ask for free, I will go for sure." (patient)

This attitude might have resulted from a negative past experience, and it would probably represent a barrier when it is necessary to contact the prescribing physician to obtain drug information. On the contrary, one pharmacist thought constant contact with the physician through telephone would allow adequate medical intervention and save the time of patient and pharmacist. But this notion was not agreed with the physicians who thought that too many of these phone calls might interrupt their works. Three pharmacists said they will still double check the obtained drug information against a second opinion.

\section{CONCLUSION}

To our knowledge, this research was the first comprehensive study to examine the strengths and weaknesses of current DICs in Egypt. It is a fact that the pharmacist in all types of practice must use resources outside the immediate area of his/her practice in Egypt due to lack of financial support in most of the pharmacy settings. Most participants expressed a need for a DIC. Unfortunately, there were no general guidelines, quality assurance units or any type of official auditing bodies to regularly monitor, support and assess the DICs which echoed in most of the developing countries. The authors have organized a meeting between the expert and the participating DICs for a feedback workshop after obtaining the final results of this study. All participants felt that they have gained benefits from this workshop and showed the willingness to improve their services.

From this core study, the building of a drug information center network with more definitive standards of services in the future is essential to provide safe, effective and cost-effective quality-assured pharmaceutical care to meet the needs and expectations of the community. To ensure the quality of information provided by the DICs, it is necessary to establish an university-based DIC to incorporate training, education and research into the existing services. The services provided for the general public should be free of charge. The limitation of the study is the small population involved in the survey due to the under establishment of clinical pharmacy in the Egyptian hospitals. However, the results and recommendations demonstrated in this study can be inspired and generalized to other developing countries that have similar health systems as in Egypt.

\section{Funding}

The authors declare receiving no financial support for this research.

\section{ACKNOWLEDGEMENT}

The authors gratefully acknowledge the participating DICs for their willingness and contributions in this study. We would like also to acknowledge final year project pharmacy students in collecting data and conducting interviews.

\section{CONFLICTS OF INTERESTS}

The authors declared no potential conflicts of interest with respect to the research, authorship, and/or publication of this article.

\section{REFERENCES}

1. Rosenberg JM, Fuentes RI, Starr CH, Kirschenbaum HL, McGuire H. Pharmacist-operated drug information centers in the United States. Am J Health Syst Pharm 1995;52:991-6.

2. Pradhan SC. The performance of drug information center at the University of Kansas medical center Kansas City, USAexperiences, and evaluation. Indian J Pharmacol 2002;34:123-9.

3. Calder G, Davies JS, McNulty H, Smith JC. Drug information network in the United Kingdom National Health Service. Am J Health Syst Pharm 1981;38:663-6.

4. Beaird SL, Coley RMR, Crea KA. Current status of drug information centers. Am J Health Syst Pharm 1992;49:103-6.

5. Rosenberg JM, Koumis T, Nathan JP, Cicero LA, McGuire H. Current status of pharmacist-operated drug information centers in the United States. Am J Health Syst Pharm 2004;61:2023-32.

6. Müllerová H, Vlček J. European drug information centerssurvey of activities. Pharm World Sci 1998;20:131-5.

7. Maguire ME, D'Arcy PF. Present drug information services in Europe including 'The two pharmacists of Verona'. Int Pharm J 1990;4:49-56.

8. Taggiasco N, Sarrut B, Doreau CG. European survey of independent drug information centers. Ann Pharmacother 1992;26:422-8.

9. World Health Organization. WHO policy perspectives on medicines: promoting rational use of medicines: core components. Geneva: WHO; 2002.

10. World Health Organization. WHO medicines strategy 2004 2007: countries at the core. Geneva: WHO; 2004.

11. Ghaibi SH, Ipema HE, Gabay MI. ASHP Guidelines on the pharmacist's role in providing drug information. Am J Health Syst Pharm 2015;72:573-7.

12. IUPHAR (the International Union of Basic and Clinical Pharmacology). Clinical pharmacology in healthcare, teaching and research. J Basic Clin Pharmacol Toxicol 2010;107:531-59.

13. Gautam K. Addressing the research-practice gap in health care management. J Public Health Management Practice 2008;14:155-9.

14. Grol R, Grimshaw J. From best evidence to best practice: effective implementation of change in patients' care. Lancet 2003;362:1225-30.

15. Tumwikirize WA, Ogwal-Okeng JW, Vernby A, Anokbonggo WW, Gustafsson LL, Lundborg CS. Access to up-to-date drug information in developing countries continues to pose problems. Pharmacoepidemiol Drug Saf 2007;16:1177-9.

16. Bergman U, Wiholm BE. Drug-related problems are causing admission to a medical clinic. Eur J Clin Pharmacol 1981;20:193-200.

17. Pirmohamed M, James S, Meakin S, Green C, Scott AK, Walley TJ, et al. Adverse drug reactions as cause of admission to hospital prospective analysis of 18820 patients. Br Med J 2004;329:15-9.

18. Griffey RT, Lo HG, Burdick E, Keohane C, Bates DW. Guided medication dosing for elderly emergency patients using realtime, computerized decision support. J Am Med Informatics Association 2012;19:86-93. 
19. Abdel-Latif MM, Sabra K. Clinical pharmacy practice in Egyptian hospitals. Am J Health Syst Pharm 2016;73:e63-6.

20. Central Agency for Public Mobilization and Statistics. Homepage. Available from: http://www.capmas.gov.eg/HomePage.aspx. [Last accessed on 01 Mar 2016].

21. Vigneshwaran E, Reddy PY, Devanna N. Drug information services to HIV/AIDS care and support centre in resourcelimited settings. Asian J Pharm Clin Res 2013;6:175-8.

22. Lacey A, Luff D. Qualitative research analysis: The NIHR RDS for the East Midlands/The NIHR RDS for Yorkshire and the Humber; 2007. p. 12-5.

23. DeSantis L, Ugarriza DN. The Concept of the theme as used in qualitative nursing research. Western J Nursing Res 2000;22:351.

24. Quinn PM. Qualitative analysis and interpretation. In: Quinn PM, editor. Qualitative research and evaluation methods. 3rd ed. California EU: Sage Publications Inc; 2002. p. 452-81.
25. Kahlke RM. Generic qualitative approaches pitfalls and benefits of methodological mixology. Int J Qual Methods 2014;13:e37-52.

26. Tavakol M, Dennick R. Making sense of Cronbach's alpha. Int J Med Edu 2011;2:53-5.

27. Hertzog MA. Considerations in determining sample size for pilot studies. Res Nursing Health 2008;31:180-91.

28. Patel H, Adepu R, Sapthagiri R, Gurumurthy P. Drugs and therapeutic information service provided by clinical pharmacists for an improved patient care: an experience from a tertiary care teaching hospital. Asian J Pharm Clin Res 2015;8:175-8.

\section{How to cite this article}

- $\quad$ Ming Ming Wen, Heba Aref, Ahmed Abozaid, Nahla Hesham Kandil, Yasmin Hussein Elsobky. Quality evaluation and survey of the essential need for drug information centers. Int J Pharm Pharm Sci 2016;8(11):137-143. 